\title{
PENGEMBANGAN SISTEM INFORMASI NILAI RAPOR PESERTA DIDIK SEKOLAH MENENGAH PERTAMA NEGERI 12 SURAKARTA
}

\author{
Daryono \\ Universitas Slamet Riyadi \\ email:cahkra2010@gmail.com
}

\begin{abstract}
Development of Report Card Value Information Systems at Surakarta State Middle School 12. is a system that provides information about report cards that are fast and accurate based on local web, thus helping speed and quality in delivering information. the menu can only be accessed by certain users, namely, teacher and administrator. The results of this study have developed a Report Card Value Information System at Surakarta State Middle School 12. The research method used by the author in this study consisted of interviews, observations (observations), literature studies, data collection, analysis phase, system design, making programs, trials, implementation test stages. Where in building this system used system development tools namely Data Flow Diagrams (DFD), Entity Relationship Diagrams (ERD) and Flowcharts and by using the PHP and HTML programming languages and MySQL as the database This web-based local school information system is designed as a solution for parties SMP Negeri 12 Surakarta, for managing report card grades, ranging from entry, storing, processing, and printing report cards.
\end{abstract}

Keywords : Information System, PHP, HTML.

\begin{abstract}
Abstrak
Pengembangan Sistem Informasi Nilai Raport pada SMP Negeri 12 Surakarta. merupakan suatu sistem yang memberikan informasi tentang Nilai Raport yang cepat dan akurat berbasis web lokal, sehingga membantu kecepatan dan kualitas dalam penyampaian informasi. menu hanya dapat diakses oleh user tertentu yaitu, Guru atau walikelas dan administrator. Pada hasil penelitian ini telah dikembangkan sebuah Sistem Informasi Nilai Raport pada SMP Negeri 12 Surakarta. Metode penelitian yang dilakukan penulis dalam penelitian ini terdiri dari Wawancara , Pengamatan (observasi), Studi pustaka, Pengumpulan data, Tahap analisa, Rancangan sistem, Pembuatan program, Uji coba, Tahap Uji Implementasi. Dimana dalam membangun sistem ini digunakan alat bantu pengembangan sistem yaitu Data Flow Diagram (DFD), Entity Relationship Diagram (ERD)dan Flowchart serta dengan menggunakan bahasa pemrograman PHP dan HTML dan MySQL sebagai databasenya Sistem informasi sekolah berbasis web lokal ini dirancang sebagai solusi bagi pihak SMP Negeri 12 Surakarta, untuk Pengelolaan nilai raport, mulai dari mengentri, menyimpan, mengolah, dan mencetak nilai rapor.
\end{abstract}

Kata Kunci : Sistem Informasi, PHP, HTML.

\section{Pendahuluan}

Di SMP Negeri 12 Surakarta untuk membuat nilai raport masih menggunakan program yang sederhana yaitu Ms Excel dengan suatu proses yang panjang yaitu Seorang guru dalam memasukkan nilainya dengan cara menulis pada daftar nilai lalu dientri diExcel,terus diprint out baru diserahkan pada walikelas.tugas wali kelas mengentri lagi untuk diolah menjadi nilai raport. Dengan permasalan di SMP N 12 Surakarta.untuk membuat nilai raport yang membutuhkan proses yang panjang.maka disini penulis mempunyai ide membuat Sistem Informasi Nilai Raport yang cepat dan akurat.

\section{Batasan Masalah}

Batasan dalam pembuatan Sistem Informasi Nilai rapor Peserta Didik SMP N 12 Surakarta adalah :
1. Objek penelitian di SMP Negeri 12

Surakarta.

2. Berbasis web lokal ini dibangun menggunakan PHP sebagai bahasa pemrograman dan MySQL sebagai Data Base.

\section{Tujuan penelitian}

Tujuan penelitian ini adalah untuk menghasilkan sistem informasi sekolah berbasis Localhost yang dapat digunakan sebagai salah satu fasilitas di sekolah untuk guru dan walikelas dalam mengentri, menyimpan, mengolah,dan mencetak nilai rapor dalam memberikan informasi kepada peserta didiknya dengan cepat dan akurat.

\section{Manfaat Penelitian}

Berdasarkan rumusan masalah, maka manfaat penelitian ini adalah: 
1. Memudahkan Guru dan Walikelas dalam mengentri, menyimpan, memproses dan mencetak nilai raport.

2. Mempercepat pengolahan data Raport.

\section{Metodologi Penelitian}

Metode penelitian yang dilakukan penulis dalam penelitian ini terdiri dari beberapa tahap, antara lain:

1. Wawancara

Penulis melakukan tanya jawab kepada bagian kurikulum, guru dan walikelas berkaitan dengan masalah yang akan dipecahkan.

2. Pengamatan (observasi)

Penulis melakuakan peninjauan secara lansung kelapangan dengan melakukan pengamatan secara langsung tentang sistem yang sedang berjalan.

3. Studi pustaka

Penulis mencari literatur yang berhubungan dengan penelitian yang dilakukan.

4. Pengumpulan data

Penulis mencari data tentang permasalahan yang terjadi ditempat tersebut.

5. Tahap analisa

Analisis kebutuhan sekolah, kebutuhan terhadap sistem yang akan di implementasikan.

6. Rancangan sistem

Perancangan ini merupakan tahap awal dalam membangun sebuah situs, seperti membuat perencanaan, perancangan, diagram alur, tujuan dan isi. situs ini dirancang dengan menggunakan PHP sebagai bahasa pemrogramannya, MySQL sebagai databasenya, dan notepad++ digunakan sebagai editor skrip program dan juga untuk mendesain Situs.

7. Pembuatan program

Setelah analisis dan rancangan sistem selesai tahap selanjutanya yaitu pembuatan program yaitu menuliskan scrip program yang disesuaikan dengan rancangan yang telah dibuat.
8. Uji coba

Mencoba mengimplementasikan system yang di buat disekolahan untuk mengetahui sejauh mana tujuan yang telah tercapai,dalam uji coba sistem dilakukan mulai penelitian terhadap kepuasan pengguna.

9. Tahap Uji Implementasi

Setelah sistem diujicobakan dan hasilnya sesuai dengan harapan maka sistem siap diimplementasikan dan digunakan oleh pihak sekolah untuk melakukan pengolahan nilai raport. Jika sistem telah memenuhi kriteria yang diharapkan maka sistem telah siap diimplementasikan, apabila sistem masih perlu disempurnakan maka akan dilakukan penyempurnaan sistem.

\section{Komponen penunjang Aplikasi}

Untuk komponen program bisa berjalan secara optimal,komponen penunjang aplikasi yang diperlukan adalah:

a. HTML merupakan bahasa standard untuk menampilkan halaman web

b. PHP merupakan software yang bersifat open source yang secara umun ditujukan untuk bahasa pengembangan web yang terintegrasi dengan kode HTML.

c. Web server,merupakan aplikasi yang digunakan untuk mengolah permintaan dari web browser kemudian mengolah semua proses yang menggunakan PHP dan menampilakn kembali pada web server

d. Basis Data,menurut Stephens dan Plew (2000), adalah mekanisme yang digunakan untuk menyimpan informasi data.

\section{Alur sistem Nilai raport peserta didik}




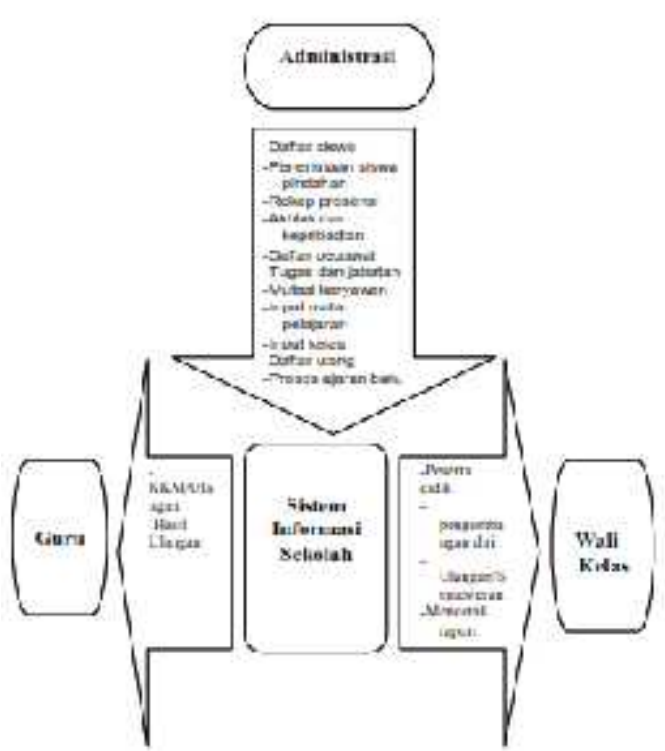

PERANCANGAN HALAMAN

a. Halaman login, merupakan halaman yang pertama kali muncul pada saat situs dibuka.

Sistem Yilai Peserta Didik

SMP Negeri 12 SURAKARTA

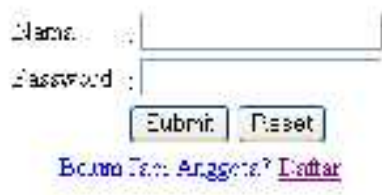

b. Halaman Registrasi, merupakan halam dimana user akan mendaftar sebagai anggota.

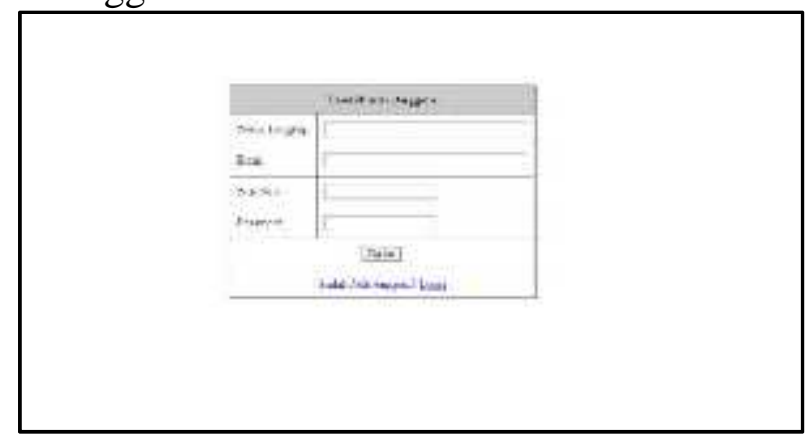

Renrargar halamar Rexngvi Atrin Kepenawalan Entri datar pegawal....

Sistem Pengisian Raport SMP Negeri 12 Surakarta

\begin{tabular}{|c|c|c|}
\hline $\begin{array}{c}\text { Viow } \\
\text { Kesiswaan }\end{array}$ & $\begin{array}{c}\text { View } \\
\text { Keprgawaia }\end{array}$ & View Utility \\
\hline \multicolumn{3}{|c|}{ DAFTAR PEGAWAI } \\
\hline \multicolumn{3}{|c|}{ Mau nombah daftar pegawai } \\
\hline \multirow{7}{*}{ Foto } & Nip & $i x \times x$ \\
\hline & Name & $\mathrm{xxx}$ \\
\hline & Alamat & $\mathrm{xxx}$ \\
\hline & No telp & $\mathrm{xxx}$ \\
\hline & No sertifikasi & i : $x x x$ \\
\hline & NIJPTK & $\mathrm{xxx}$ \\
\hline & N'WP & $x x x$ \\
\hline
\end{tabular}

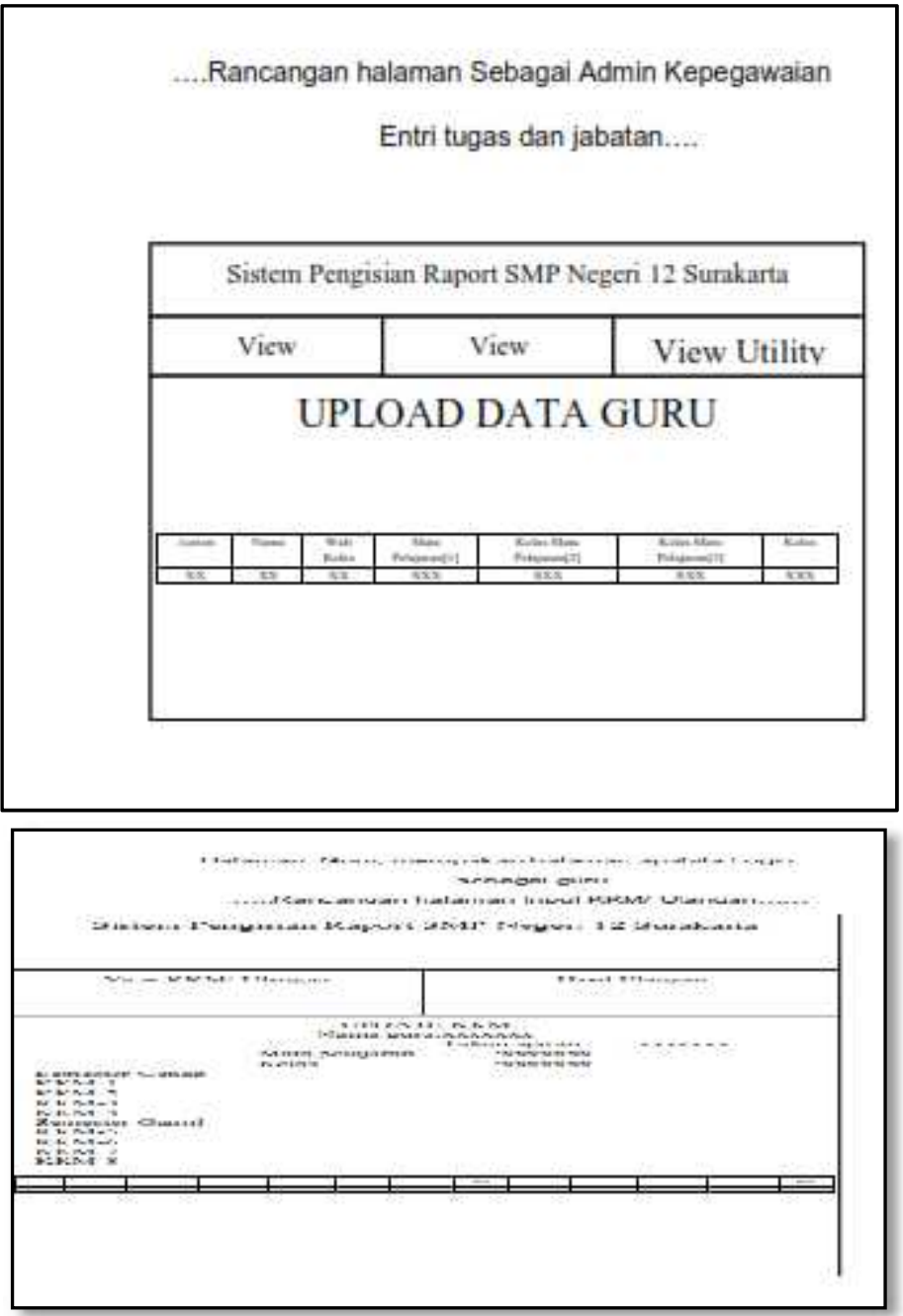




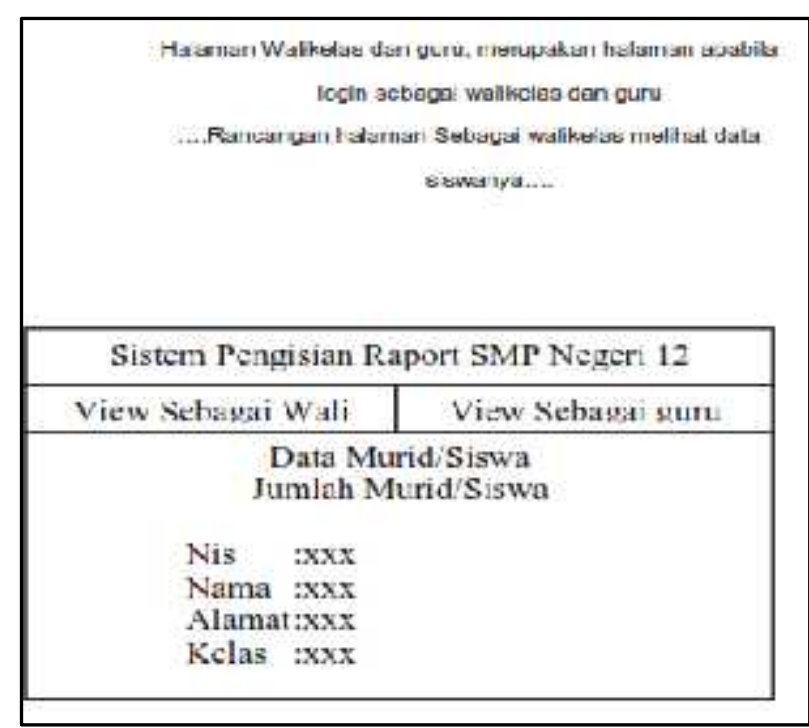

\section{Uji coba sistem}

Uji coba program ini dilakukan oleh beberapa perwakilan dari pihak bagian kurikulum sebagai administrator,Guru dan Walikelas Di SMP Negeri 12 Surakarta untuk mencoba apakah program yang dibuat oleh penulis sesuai dengan kebutuhan sekolah

1. Ini adalah tampilan login pertama yang harus diisi oleh administrator,Guru dan walikelas apabila belum terdaftar sebagai anggota

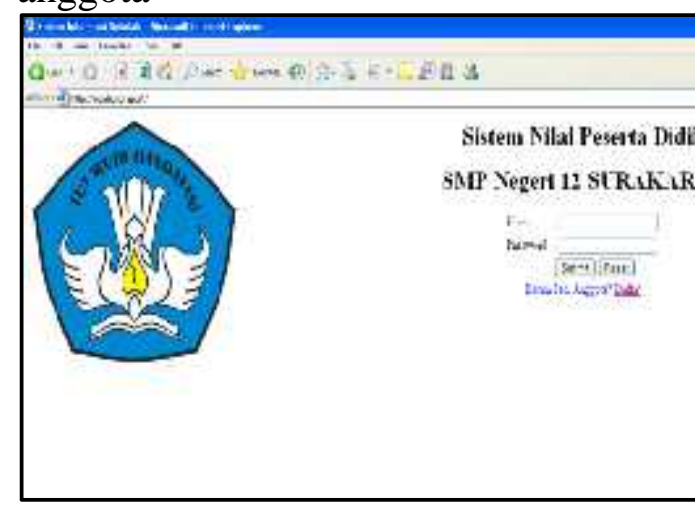

2. Setiap user yang akan membuka situs sistem informasi sekolah harus sudah terregristasi dalam database sekolah. Jika belum masuk dulu kehalaman regristasi dengan cara klik kata daftar ( Belum Jadi Anggota? Daftar )dan setelah berhasil dengan tampilan Sbb:

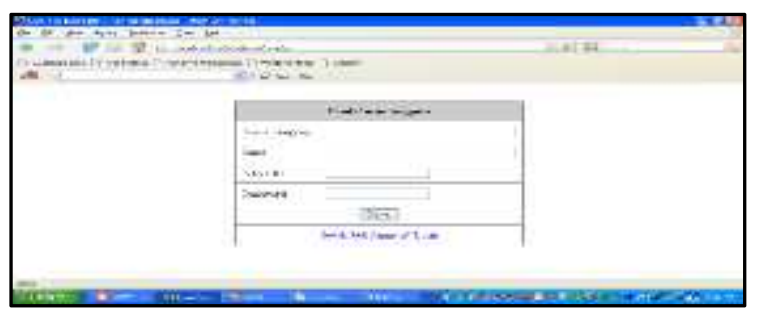

3. Ini adalah gambar seorang bagian kurikulum yang mencoba program yang sedang mengentrikan data,User sebagai Admin yang sedang mengentri data.

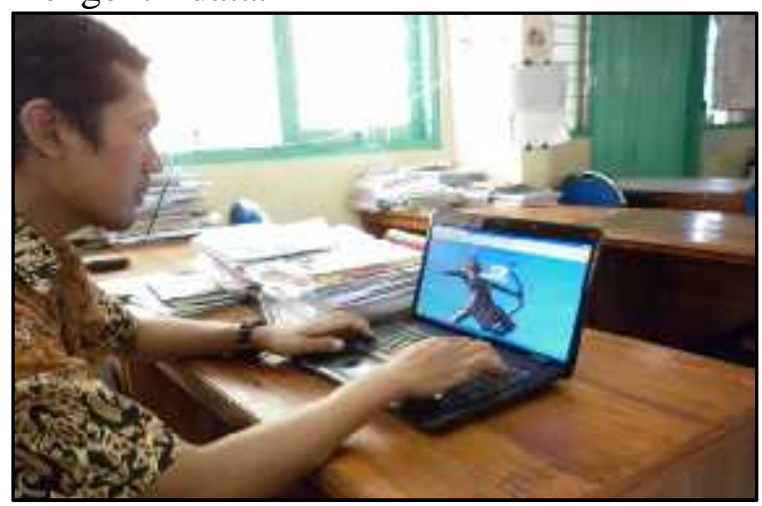

Setelah selesai login sebagai admin dan mengisikan password berhasil maka akan muncul menu tampilan sebagai berikut:
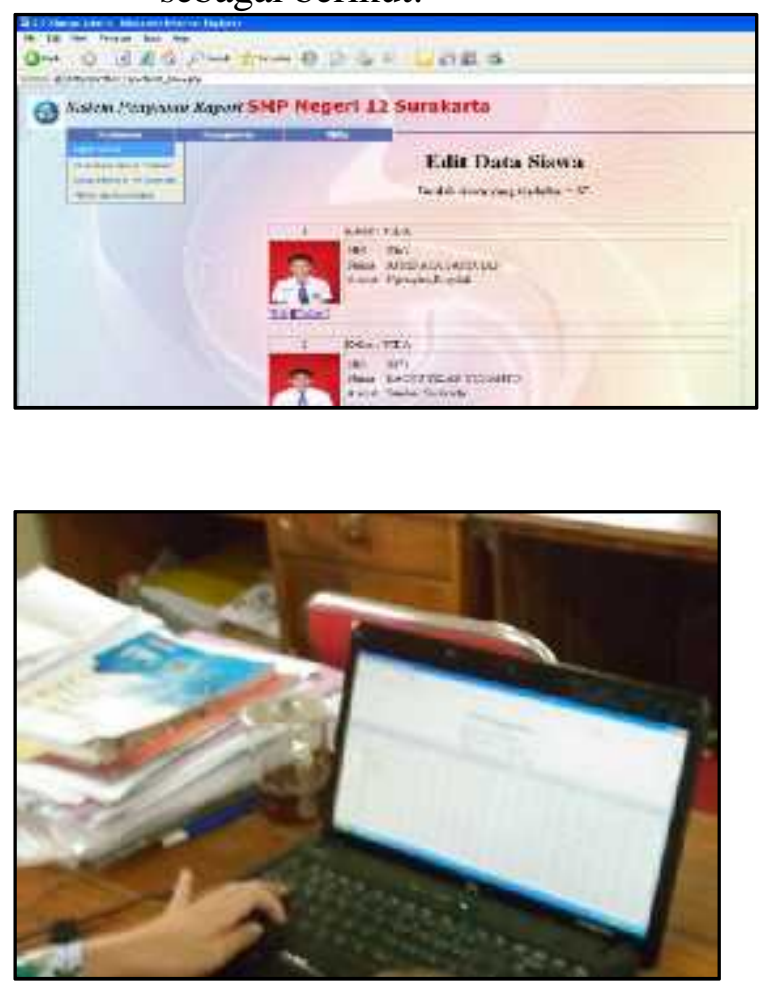

Gambar ini adalah petugas administrator yang sedang mengentrikan program mulai dari daftar Siswa,penerimaan siswa 
kepribadian,daftar pegawai,tugas dan jabatan,mutasi karyawan,input mata pelajaran dan input kelas.

4. Ini adalah gambar seorang Guru yang mencoba program yang sedang mengentrikan data,User sebagai guru dengan nama fentina dan password fentina.

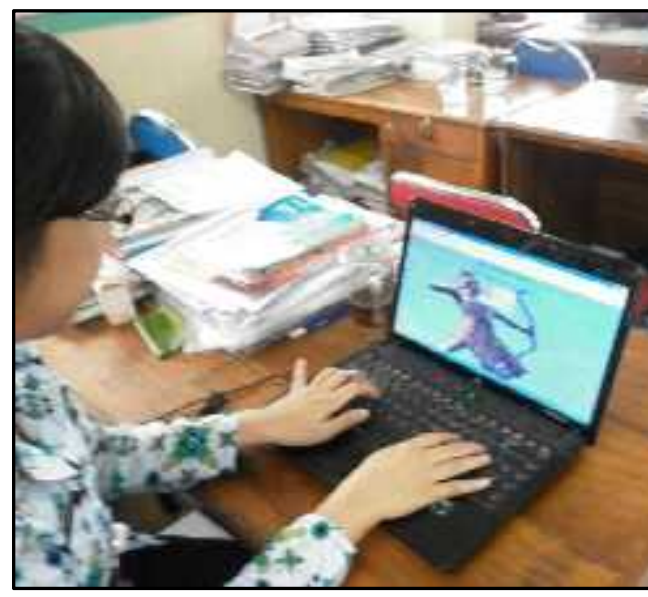

Setelah berhasil login sebagai guru berhasil maka akan ada tampilan menu KKM dan Nilai ulangan :
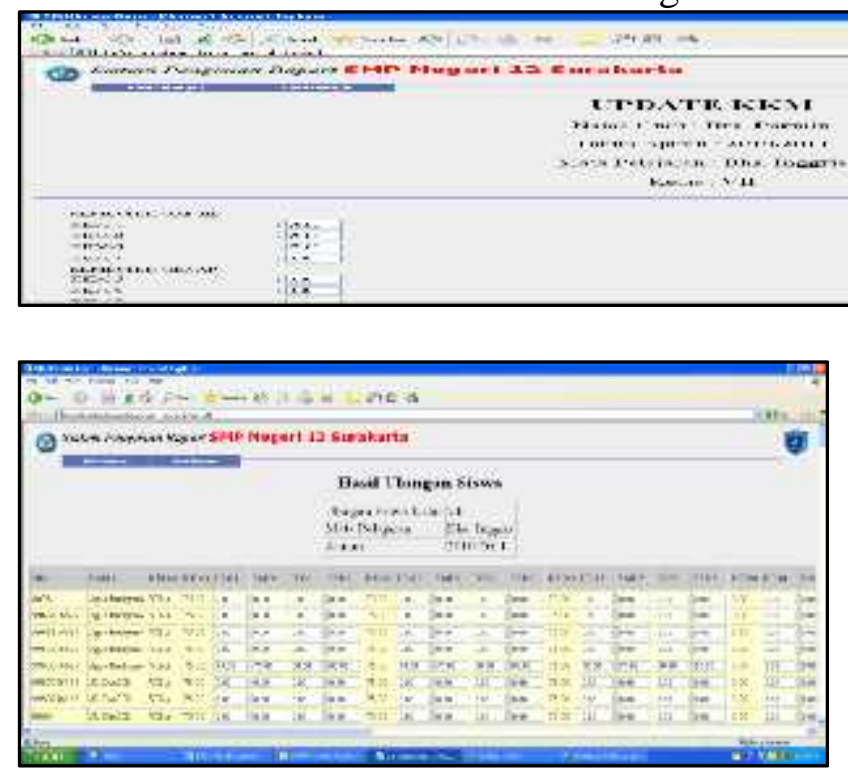

Gambar ini adalah seorang Guru yang mengentrikan KKM Mata pelajaran dan nilai ulangan mata pelajaran yang mereka ampu. Setelah selesai pilih menu update untuk menyimpan data

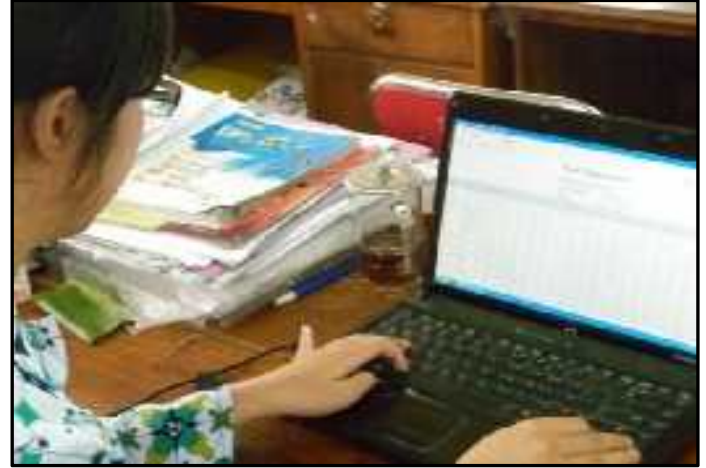

5. Ini adalah gambar seorang Guru dan Juga bertugas sebagai Walikelas yang sedang mencoba program mengentrikan data, User pramesti dan password agus.

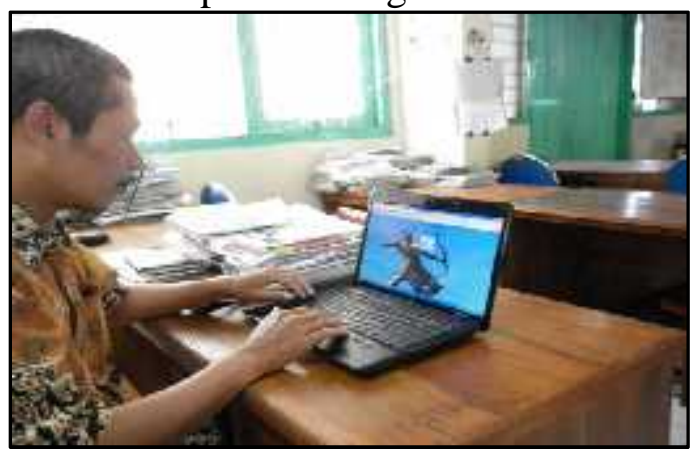

Kalau berhasil maka akan ada tampilan menu sebagai berikut

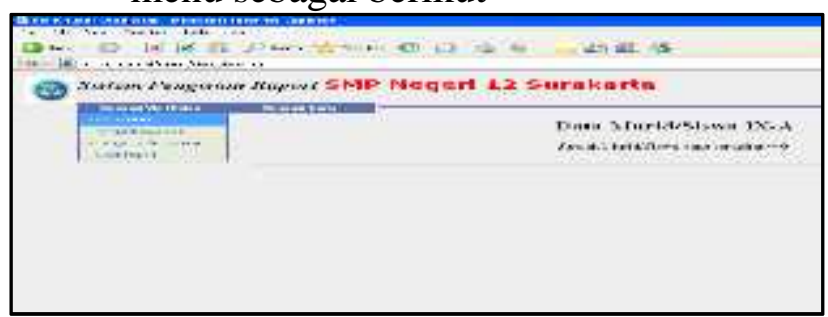

Setelah berhasil login sebagai Guru dan Walikelas maka aka nada tampilan menu siswa/murid,pengembangan

diri,ulangan dan semesteran,cetak Raport.Setelah semua data selesai dan dipilih menu update semua dari Admin,guru dan walikelas bertugas Mencetak Nilai raport dengan hasil sebagai berikut 


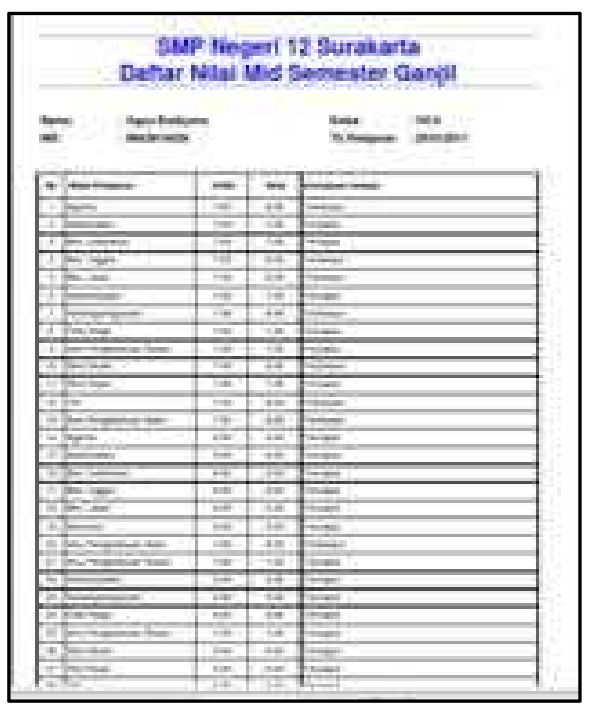

\section{Kesimpulan}

Dari hasil penelitian ada beberapa kesimpulan yang dikemukakan sebagi berikut:

1. Sistem informasi sekolah berbasis web lokal ini dirancang sebagai solusi bagi pihak SMP Negeri 12 Surakarta, untuk Pengelolaan nilai raport, mulai dari mengentri, menyimpan, mengolah, dan mencetak nilai rapor.

2. Sistem informasi sekolah berbasis web dibuat bersifat internal, artinya pengguna program ini hanya kalangan Sekolah yang memiliki hak akses terhadap sistem tersebut yaitu administrasi, guru, walikelas.

3. Dengan di implementasikannya Sistem Informasi Nilai Raport, Pengelolaan Data nilai raport di selesaikan dalam waktu yang lebih cepat dan data yang diperoleh lebih akurat.

\section{Saran}

Dari Kesimpulan yang diperoleh maka disarankan bagi peneliti selanjutnya :
Sistem yang dibuat ini masih terbatas pada penginformasian Nilai Raport, Untuk peneliti selanjutnya dapatmmerancang dan membangun Sistem informasi sekolah atau laporan data-data yang lebih meluas dalam cakupan sistem informasi sekolah di SMP Negeri 12 Surakarta.

\section{DAFTAR PUSTAKA}

Edi Winarno ST, M.Eng.2004.Easy Web Programming With PHP Plus Html, Jakarta.Elex Media koputindo.

Eko priyo Utomo, ST. 2006.125 Tips Menguasai PHP, Jakarta.Yrama Media.

Heni A. Puspitasari.2005 Pemmrograman web Database dengan PHP \& MySQL,Yogyakarta.Skripta Media Creative.

Jogiyanto,HM. 2001. Analisa dan Desain Sistem Informasi. Yogyakarta.Andi offset.

Kadir, Abdul. 2000. Pengenalan Sistem Informasi, Yogyakarta. Andi offset.

Ridwan Sanjaya.2009 Membuat Laporan PDF untuk Aplikasi Web dengan PHP 5,Jakarta. Elex Media Koputindo.

Yeni Kustiyahsih, Devie Rosa Anamisa. 2005.Pemrograman Basis Data Berbasis Web Menggunakan PHP \& MySQL ,Yogyakarta.Graha Ilmu.

Saputri, Devy Listisari.Jurnal Knowledge Management Bagi Sistem Informasi Perpustakaan Universitas Gadjah Mada. UGM Press, Yogyakarta. 2009.

Nataniel DengenDyna Marisa Kh. Jurnal Informatika Mulawarman Vol 4 No. 2 Juli 200918 Program Studi Ilmu Komputer Universitas Mulawarman Sistem Informasi Akademik Berbasis Web SMP Negeri 4 Samarinda. 